\title{
EXPERIÊNCIAS COTIDIANAS DE UM DEFICIENTE VISUAL LICENCIANDO EM CIÊNCIAS E SUA REALIDADE INCLUSIVA (DEFICIÊNCIA VISUAL E INCLUSÃO)
}

\author{
DAILY EXPERIENCES OF A VISUALLY IMPAIRED UNDERGRADUATE STUDENT \\ IN SCIENCE AND HIS INCLUSIVE REALITY \\ (VISUAL IMPAIRMENT AND INCLUSION)
}

\section{EXPERIENCIAS COTIDIANAS DE UN DISCAPACITADO VISUAL ESTUDIANTE DE CIENCIAS Y SU REALIDAD INCLUSIVA (DISCAPACIDAD VISUAL E INCLUSIÓN)}

\author{
Jorgea Tânia Amazonas Barros ${ }^{1}$ \\ Centro Universitário Leonardo da Vinci - UNIASSELVI \\ Fabricio Valentim da Silva² \\ Universidade Federal do Amazonas - UFAM \\ Salomão Amazonas Barros ${ }^{3}$ \\ Instituto Federal de Educação, Ciência e Tecnologia do Amazonas - IFAM
}

\begin{abstract}
Resumo
O processo de inclusão escolar e social ainda é uma das grandes dificuldades enfrentadas por pessoas com necessidades educacionais especiais (NEE). Nas universidades federais brasileiras, o ingresso de pessoas com deficiência é possível a partir de um conjunto de medidas, previstas em

\footnotetext{
${ }^{1}$ Graduada em Licenciatura em Ciências: Química e Biologia (Universidade Federal do Amazonas) com especialização em Educação Especial Inclusiva (Centro Universitário Leonardo da Vinci) e especialização em andamento em Docência no Ensino Superior (Centro Universitário Leonardo da Vinci). Possuo experiência em docência no ensino médio na área de. Biologia Geral com ênfase em Biologia Geral. ORCID: https://orcid.org/0000-0002-6959-1676. Lattes: http://lattes.cnpq.br/7590016631042484. E-mail: barrustania23@gmail.com.

${ }^{2}$ Graduação em Pedagogia pela Universidade Federal de Viçosa (2004) e Mestrado em Educação pela Universidade Federal de Uberlândia (2007), Doutor em Educação - Université de Montréal (2019), Professor Adjunto III no Instituto de Ciências Exatas e Tecnologia da Universidade Federal do Amazonas (ICET/UFAM). Atualmente desenvolve o projeto Mentoria de Professores de Ciências Iniciantes aprovado na Chamada MCTIC/CNPq № 05/2019 - PROGRAMA CIÊNCIA NA ESCOLA, Ensino de Ciências na Educação Básica com o número de Processo: 441001/2019-0. ORCID: https://orcid.org/0000-0001-8721-7103. Lattes: http://lattes.cnpq.br/7907037135314095. E-mail: fvalentims@yahoo.com.br.

${ }^{3}$ Possui graduação em Letras pelo Instituto de Ciências Humanas e Letras, da Universidade Federal do Amazonas (2008). É especializando em Metodologia do Ensino Superior e Educação a distância pela Faculdade Educacional da Lapa. Atualmente é professor titular do Instituto Federal de Educação, Ciência e Tecnologia do Amazonas. ORCID: https://orcid.org/0000-0003-3413-2469. Lattes: http://lattes.cnpq.br/3538389008375587. E-mail: salomaoamazonas@gmail.com.
} 
legislação, que asseguram não só o acesso, mas também condições plenas de participação e aprendizagem a todos os estudantes. O objetivo do presente trabalho foi conhecer as reais condições de inclusão de um aluno com deficiência visual de um curso de Ensino Superior de uma universidade federal, verificando se o acadêmico enfrentou barreiras de acessibilidade e identificando os fatores que garantiram a permanência do aluno no curso. Para tal, empregou-se a metodologia de aplicação de questionário aberto e abordagem qualitativa, no qual foram considerados seis tipos de acessibilidades: acessibilidade atitudinal, arquitetônica, comunicacional, instrumental, metodológica e programática. O procedimento utilizado foi a realização de uma entrevista semiestruturada, seguida de análise dos conteúdos coletados. Os resultados mostraram que é necessário investimento na formação de professores e planejamento em ações de conscientização sobre educação inclusiva junto à comunidade acadêmica, de maneira que sejam criadas condições de permanência para que os alunos com NEE concluam com êxito a sua graduação.

Palavras-chave: Acessibilidade na Graduação; Acesso e Permanência; Deficiência Visual.

\begin{abstract}
Social and scholar inclusion process is still one of the major difficulties faced by people with special educational needs (SEN). At Brazilian federal universities, the entry of people with disability is possible based on a set of measures, provided for in legislation, that ensure not only access, but also full participation and learning conditions for all students. The objective of this study was to identify the real conditions of inclusion of a visually impaired student from a higher education course at a federal university, checking if the undergraduate student faced accessibility barriers and identifying the factors that guaranteed the student's permanence in the course. For this purpose, an open questionnaire and a qualitative approach was used as methodology, in which six types of accessibility were considered: attitudinal, architectural, communicational, instrumental, methodological and programmatic accessibility. The procedure was a semi-structured interview followed by an analysis of the collected contents. The results showed that it is necessary to invest in teacher training and planning actions to raise awareness about inclusive education with the academic community, in order to create permanence conditions for students with SEN in order to successfully complete their graduation.
\end{abstract}

Keywords: Accessibility in Graduation; Access and Permanence; Visual Impairment.

\title{
Resumen
}

El proceso de inclusión escolar y social sigue siendo una de las grandes dificultades que enfrentan las personas con necesidades educativas especiales (NEE). En las universidades federales brasileñas, la admisión de personas con discapacidad es posible mediante un conjunto de medidas, previstas en la legislación, que garantizan no solo el acceso, sino también las condiciones completas para la participación y el aprendizaje de todos los estudiantes. El objetivo del presente trabajo era conocer las condiciones reales de inclusión de un estudiante con discapacidad visual de un curso de educación superior en una universidad federal, verificar si el estudiante universitario enfrentaba barreras en la accesibilidad e identificar los factores que garantizaban la permanencia del estudiante en el curso. Para ello, se utilizó la metodología de aplicación de un cuestionario abierto y un enfoque cualitativo, en el que se consideraron seis tipos de accesibilidad: accesibilidad actitudinal, arquitectónica, comunicacional, instrumental, metodológica y programática. El procedimiento utilizado fue realizar una entrevista semi estructurada seguida de un análisis de los contenidos recopilados. Los resultados mostraron que es necesario invertir en acciones de capacitación y planificación docente para crear conciencia sobre la educación inclusiva con la comunidad académica, a fin de crear condiciones de permanencia para que los estudiantes con NEE completen con éxito su graduación. 
Palabras clave: Accesibilidad en la Graduación; Acceso y Permanencia; Deficiencia Visual.

\section{INTRODUÇÃO}

A Educação Inclusiva, no Brasil, definida pela Política Nacional de Educação Especial como modalidade transversal a todos os níveis, etapas e modalidades de ensino, possui em seu próprio nome o caráter essencialmente humano da não segregação entre pessoas, sendo sua função: a disponibilização de todos os recursos e serviços de acessibilidade, atendimento educacional especializado complementar à formação dos estudantes com deficiência (MEC, 2008).

Assim, na educação superior brasileira, o ingresso de estudantes com necessidades educacionais especiais (NEE) na rede federal de ensino resulta da aplicação de um conjunto de medidas legais que Ihes possibilita o acesso, a permanência e a participação plena, prevendo-lhes a oferta de condições e atendimentos adequados para que possam garantir o seu aprendizado igualitário (BRASIL, 2008).

Desse modo, ao assumir o compromisso de assegurar as condições plenas de participação e aprendizagem aos estudantes com NEE, as Instituições de Ensino Superior (IES) evidentemente têm a obrigatoriedade de cumprir os aspectos normativos e as orientações políticas e pedagógicas que lhes são inerentes. Dentre as medidas legais que preveem o aprendizado igualitário destacam-se:

- A Constituição Federal de 1988, em que os Arts. 205, 206 e 208 dão a garantia do direito de todos à educação, tendo como princípio do ensino a igualdade de condições para o ingresso e a permanência na escola, assegurando acesso aos níveis mais elevados do ensino, da pesquisa e da criação artística, segundo a capacidade de cada um;

- A Convenção da Guatemala/2001, em que o Art. $1 .^{\circ}$ prevê impossibilidade de tratamento desigual com base na deficiência e define como discriminação toda diferenciação, exclusão ou restrição baseada na deficiência;

- O Decreto n. 6.949/09, que ratifica, como Emenda Constitucional, a Convenção sobre os Direitos das Pessoas com Deficiência (ONU, 2006), a qual determina o acesso a um sistema educacional inclusivo em todos os níveis.

A partir desses pressupostos educacionais de inclusão, tem sido registrado um crescente número de matrículas de alunos com NEE, em Instituições Federais de Ensino Superior (IFES). No ano de 2017, o Ministério da Educação por meio do censo educacional 
verificou um total de 10.667 universitários desse público com NEE, perfazendo 4.019 estudantes a mais em relação ao ano de 2013. Desse quantitativo, aqueles que possuem deficiência visual e frequentam regularmente cursos presenciais e a distância dividem-se em três grupos, sendo 449 pessoas cegas, 3.419 baixa visão e 37 surdo-cegas (INEP, 2018).

Por outro lado, entre os anos de 2005 e 2011, o Governo Federal propôs às IFES o Programa Incluir - Acessibilidade na Educação Superior, o qual, por meio de editais, selecionava instituições que atendiam às exigências do programa para disponibilização de apoio financeiro à criação de núcleos de acessibilidade. No ano de 2012, esses recursos começaram a ser repassados diretamente às IFES, objetivando viabilizar 0 desenvolvimento de uma Política de acessibilidade ampla e articulada (BRASIL, 2015).

O Programa Incluir é um excelente incentivador financeiro, mas sozinho torna-se insuficiente, pois essas ações de inclusão e acessibilidade só poderão ser efetivadas por meio de políticas destinadas às características individuais dos alunos (ANACHE; MACIEL, 2017).

É possível constatar, preliminarmente, que tem crescido o número de alunos com NEE que conseguem acessar um curso de graduação e que existem políticas públicas de inclusão e acessibilidade necessárias que preveem a garantia da permanência desse aluno, resta-nos investigar como está sendo desenvolvido esse trabalho de inclusão em ambiente acadêmico.

Nessa perspectiva, o Instituto Nacional de Estudos e Pesquisas Educacionais Anísio Teixeira (INEP) criou o documento orientador das comissões e avaliações in loco intitulado como: Referenciais de Acessibilidade na Educação Superior e a Avaliação In Loco do Sistema Nacional de Avaliação da Educação Superior (SINAES) (INEP, 2013).

Este documento tem o propósito de orientar os avaliadores de cursos superiores acerca de questões pertinentes à acessibilidade em seus diferentes níveis, levando em consideração tipologias de acessibilidades que chamam a atenção para o cumprimento dos preceitos conceituais e legais da educação inclusiva nas IES. Entre elas estão:

- Acessibilidade Atitudinal - Interesse por parte dos gestores da instituição em implementar ações e projetos relacionados à acessibilidade em toda a sua amplitude. A priorização de recursos para essas ações é um indicativo da existência dessa acessibilidade.

- Acessibilidade Arquitetônica - Rampas, piso tátil, sinalização em alto-relevo, elevadores em condições de uso, entre outros. 
- Acessibilidade Metodológica - Processos de diversificação curricular, flexibilização do tempo e utilização de recursos para viabilizar a aprendizagem de estudantes com deficiência.

- Acessibilidade Comunicacional - Uso de Braile na sala de aula (quando se trata de alunos cegos).

- Acessibilidade Programática - Processos de sensibilização, informação, conhecimento e a aplicação dos dispositivos legais e políticas relacionadas à inclusão e à acessibilidade de estudantes com deficiência na educação superior.

- Acessibilidade Instrumental - Superação das barreiras nos instrumentos, utensílios e ferramentas de estudo.

Nesse sentido, Duarte et al. (2013) ressaltam que a existência das leis de inclusão é importante e necessária à educação para todos os níveis de ensino, mas o problema da sociedade atual está em efetivar e executar essas leis. Por mais que existam legislações implementando grande parte das IFES, ainda são escassos os estudos analisando a situação dos estudantes com deficiência diante dessas políticas.

Em estudos realizados, Nepomoceno e Szezerbatz (2018) revelaram que, apesar das mudanças atuais nessa configuração, a inclusão em instituições de ensino superior tem representado um grande desafio tanto para os alunos com NEE quanto para os professores. Problemas, como a falta de profissionais qualificados, a carência de materiais específicos, a inadequação dos espaços físicos juntamente às práticas pedagógicas realizadas de forma indiferente, vêm prejudicando o ensino-aprendizado desse público-alvo.

Autores, como Castro; Nascimento; Oliveira (2011) e Santos (2012), declaram que, além dos fatos já mencionados, também existe a discriminação com essas pessoas em instituições públicas de ensino superior. Segundo Fachinetti (2018); Holanda e Paiva (2018); Almeida e Ferreira (2018); Anache e Cavalcante (2018) e Cabral (2017), para que se crie uma cultura viável ao acesso e à permanência desses alunos, são necessários o planejamento, a execução, a manutenção e a revisão de práticas inclusivas.

Segundo Pimenta (2017), é fundamental que se ouçam os alunos com NEE para que se conheça a sua real condição de inclusão, isso possibilita identificar fatores que interferem no acesso e na permanência desses estudantes.

[...] na maioria dos estudos realizados não (sic) tem priorizado a escuta aos estudantes com deficiência visual. [...] existem algumas lacunas que precisam ser preenchidas, dentre elas, pode-se levantar: como tem se caracterizado o acesso e a permanência destes estudantes nas IES brasileiras? Que fatores vêm interferindo no acesso e na permanência destes estudantes nas IES? (PIMENTA, 2017, p. 14). 
Para tanto, nesta pesquisa, analisamos a trajetória de um estudante com deficiência visual de curso superior, a partir dos relatos e percepções inclusivas do discente. Tendo como objetivos: conhecer as reais condições de inclusão de um aluno com NEE de uma universidade federal; verificar se o acadêmico enfrentou barreiras de aprendizado; e identificar os fatores que garantiram a sua permanência no curso.

A ideia do tema ocorreu após uma revisão sistemática, onde foi observada a escassez de estudos no que se refere ao ponto de vista do aluno com deficiência sobre as suas reais condições de inclusão em ambiente de Ensino Superior. Estudos como este podem contribuir na condução de um possível aprimoramento dos serviços de apoio ofertados pelas universidades a este segmento específico de educando.

Por isso, o presente trabalho foi organizado em cinco tópicos. O primeiro e o segundo se referem respectivamente à introdução e fundamentação teórica e à descrição do modo como ocorreram a elaboração e a realização desse estudo. O terceiro foi divido nas seções: Ingresso do aluno deficiente visual na universidade; Barreiras de acessibilidades encontradas pelo aluno; Fatores que garantiram a permanência do aluno no curso e Reais condições de inclusão do aluno deficiente visual na universidade. O quarto aponta algumas reflexões a respeito da situação de inclusão do estudante deficiente visual. $\mathrm{E}$ o quinto compõe-se da conclusão e das considerações pertinentes aos resultados do trabalho.

\section{MÉTODO}

O estudo foi realizado com um aluno portador de deficiência visual (cegueira total em ambos os olhos), que tem como causa da deficiência a Retinose Pigmentar. Tal doença é uma distrofia retiniana hereditária na qual há perda progressiva de fotorreceptores do epitélio da retina (camada interna que reveste a câmara ocular), sendo, o quadro mais severo, a perda da função visual (TAYAH et al., 2004).

O sujeito da pesquisa é estudante regular do curso de Licenciatura em Ciências: Química e Biologia, do Instituto de Ciências Exatas e Tecnologia (ICET), da Universidade Federal do Amazonas (UFAM), campus de Itacoatiara, localizado na mesorregião central do Estado do Amazonas (AM), distante, ao leste, 277 km da capital Manaus.

Os artigos utilizados para referenciar este estudo foram selecionados nas bases de pesquisas: Scientific Electronic Library Online (SCIELO); Google Acadêmico e Biblioteca Digital de Teses e Dissertação (BDTD), empregando como palavras-chave: acessibilidade na educação superior; inclusão de deficientes visuais na universidade; estudo de caso 
sobre inclusão em instituição de ensino; núcleos de acessibilidade em instituições brasileiras.

Dos instrumentos de coletas de dados, optou-se pela metodologia de elaboração e aplicação de um questionário aberto com 15 (quinze) perguntas relacionadas à inclusão e acessibilidade nas IES. Para a elaboração das perguntas, teve-se como referência o documento "Referenciais de Acessibilidade na Educação Superior e a Avaliação In Loco do Sistema Nacional de Avaliação da Educação Superior (SINAES), de 2013".

Foram considerados seis tipos de acessibilidades que constam no referido documento: Acessibilidade atitudinal, arquitetônica, comunicacional, instrumental, metodológica e programática. A entrevista foi realizada e gravada nos dias 3 e 4 do mês de maio de 2019, na residência do estudante sujeito da pesquisa.

Para a realização das análises dos resultados, as respostas foram divididas e discutidas nas seguintes seções:

- Ingresso do aluno com deficiência visual na universidade.

- Barreiras de acessibilidades encontradas pelo aluno.

- Fatores que garantiram a permanência do aluno no curso.

- Reais condições de inclusão do aluno deficiente visual na universidade.

Após transcrição e releitura, verificou-se se a universidade atendia às leis de acessibilidade vigentes e cumpria as orientações que constam no documento já citado "Referenciais de acessibilidade das IES".

\section{RESULTADOS E DISCUSSÃO}

\section{INGRESSO DO ALUNO COM DEFICIÊNCIA VISUAL NA UNIVERSIDADE}

Temos então o seguinte relato:

Meu ingresso [...] se deu por meio do [...] ENEM, [...] meses antes do exame, o INEP entrou em contato comigo confirmando meu Código Internacional de Doenças (CID) e [...] as solicitações de atendimento especial [...] obtive nota de 794 [...] concorri por ampla concorrência, [...] primeira opção Licenciatura em ciências: Química e Biologia (1.15).

Verifica-se na narrativa do estudante que os recursos disponibilizados para a realização da prova do Exame Nacional do Ensino Médio (ENEM) foram eficientes, de maneira que a sua condição de deficiência não dificultou o seu ingresso na instituição.

Nos processos seletivos em cursos ofertados por instituições de ensino, a Lei no. 13.146/2015, no Art. 30, determina a disponibilização de recursos de acessibilidade 
adequados e previamente solicitados e escolhidos pelo candidato com deficiência. (BRASIL, 2015).

\section{BARREIRAS DE ACESSIBILIDADES ENCONTRADAS PELO ALUNO NA INSTITUIÇÃO}

No ato da matrícula, o aluno fez a entrega do laudo e comunicou à instituição as suas limitações, mas foi informado pelo servidor, que o atendeu, o fato da universidade não disponibilizar nenhum tipo de atendimento a alunos com NEE.

[...] No ato da matrícula [...] entreguei [...] o laudo [...] referente à cegueira [...] me foi informado que não havia nenhum tipo de atendimento especial [...] O primeiro dia de aula de nivelamento, eu perdi [...] fui até a coordenação acadêmica, me direcionaram para o setor administrativo [...]. A partir do segundo dia, [...] me foi disponibilizado um aluno do instituto que fazia parte do Programa Bolsa Trabalho, o qual ficou me auxiliando na mobilidade apenas. (2.15).

[...] houve [...] uma capacitação voltada para acessibilidade e inclusão [...] não estava acontecendo por minha causa e sim por conta do cronograma do projeto que ele [o palestrante] estava sendo executado, [...] tratava-se de uma coincidência o projeto estar ali diante de uma demanda que estava sendo representada por mim [...] e não era voltado apenas para deficiente visual, [...]. Depois dessa [...], houve mais umas duas, no mesmo nível com o mesmo palestrante. (3.15).

Os relatos do aluno nos levam a refletir sobre como as IFES estão trabalhando para que se diminuam as barreiras de acessibilidade em ambiente de ensino, já que existe uma política de inclusão que garante o acesso e a permanência dos alunos com NEE. Por outro lado, o Programa Incluir, proposto pelo MEC desde 2005, tem financiado Núcleos de Acessibilidade para as instituições federais, mas vale ressaltar que esse financiamento só é liberado diante da demanda que a universidade apresenta (BRASIL, 2008).

As barreiras físicas também existiam, as quais impediam a mobilidade autônoma do aluno no espaço acadêmico.

[...] Encontrei todo tipo de dificuldade de acessibilidade na estrutura física do instituto. Não havia piso tátil, não havia sinalização em alto-relevo, não havia elevadores em condições de uso [...]. Após alguns semestres, puseram o piso tátil [...]. Existem também barreiras aéreas como galhos de árvores que bloqueiam parte do acesso de uma caminhada sem barreiras pelos corredores livres do instituto (4.15).

Em descumprimento às leis de acessibilidade, fica evidente que a instituição necessita de melhorias no sentido de se tornar um espaço acessível a alunos com deficiência visual, para que estes possam utilizá-lo de maneira independente e, assim, 
efetivar a garantia dos direitos já conquistados. A ABNT NBR 9050 dita todas as regras que devem ser seguidas para se ter um ambiente acessível.

Das barreiras de cunho pedagógico, detectaram-se os seguintes relatos:

Sobre a relação professor/aluno, durante toda a minha trajetória, [...] somente seis professores tiveram uma boa relação comigo, [...] não fiz uso de materiais didáticos. [...] eu destaco a disciplina de Anatomia, [...] as explicações eram realizadas no meu próprio corpo, [...] uma explicação de contato, [...] Também do professor de inglês instrumental, apesar de a disciplina possuir conteúdo totalmente teórico, mas ele ilustrava essa teoria. Os outros quatro professores [...] me proporcionaram um ensino acessível. A relação com os colegas assim como a com os outros professores, que eu não incluí nesse grupo, era difícil, [...] eram indiferentes, me ignoravam. [...] (5.15).

Com exceção das aulas de Química orgânica experimental, nas aulas de laboratório eu sou apenas ouvinte. [...]. Não há interação com o professor e nem com os colegas. [...] nas aulas de Química orgânica experimental. [...] a professora [...] me levava para uma outra bancada e simulava o experimento completo, detalhadamente, [...] e a relação que eu tenho com ela é muito boa até mesmo fora da sala de aula (6.15).

[...], durante toda a minha trajetória foi muito difícil participar de projetos de pesquisa e extensão. Fui à procura, por diversas vezes, [...], eles sempre diziam que iriam entrar em contato [...], mas eu nunca fui chamado. [...] um professor aceitou que eu participasse, mas também não me deu suporte algum. [...], um professor que conhecia a minha dificuldade resolveu intervir junto a seus colegas para que eu pudesse participar (7.15).

As minhas primeiras avaliações foram do modo tradicional. Os professores não sabiam como me avaliar [...]. Me entregavam uma avaliação impressa, faziam uma ampliação, achando que a minha deficiência visual era resolvida com [...] ampliação. [...] Após [...] uma conversa [...], um dos professores propôs [...] uma avaliação oral, [...] independente se fossem cálculos ou alguma teoria. [...]. No momento todas as avaliações são realizadas no modelo do ENEM, [...] Nem sempre eu acho que chegamos a um modelo ideal de avaliação, porque muitas vezes o ledor não sabe descrever o conteúdo da prova [...]. Penso que se houvesse a oferta de formação [...], eles poderiam conhecer outras metodologias [...] (8.15).

Eu classifico como a principal dificuldade dos professores, que trabalharam comigo durante o curso, a falta de formação em educação inclusiva. Foi um desafio para aqueles que se interessaram em me proporcionar um ensino acessível. [...] teve a resistência dos demais professores a adotar ou a ir em busca por didáticas mais inclusivas e. [houve] a inflexibilidade em desenvolver uma interação inclusiva dos conteúdos dentro da sala de aula (9.15).

A fala do estudante mostra a importância de um professor com perfil proativo na sala de aula, sem o qual, inviabiliza-se a inclusão, embora haja o acesso às aulas, o aluno é prejudicado, como ocorreu no decorrer de várias disciplinas curriculares. Alguns docentes, 
mesmo sem possuírem formação inclusiva, viram na situação a oportunidade de adquirir experiências sobre inclusão, isso fez uma grande diferença na vida acadêmica do aluno.

Estrela (2017) cita a discriminação como um dos fatores que também contribuem diretamente para a exclusão desses alunos em instituições de ensino. Trata-se não somente da atitude daqueles professores que excluíram o aluno dos projetos de pesquisa e extensão, mas também da indiferença praticada pelos colegas na formação de grupos de trabalho em sala de aula.

Segundo a autora, isso acontece pelo fato dessas pessoas considerarem o aluno com NEE incapaz de realizar as atividades. Para Holanda e Paiva (2018), o papel da instituição sobre essa situação é fundamental no processo de elaboração de ações que contribuam para a conscientização da comunidade acadêmica sobre a inclusão, visto que a universidade é um espaço de produção de conhecimento e formação de pessoas.

Para Silva e Navarro (2012, p. 95), “A relação professor-aluno é uma forma de interação que dá sentido ao processo educativo, uma vez que é no coletivo que os sujeitos elaboram conhecimentos. Por isso, o docente precisa refletir a todo o momento sobre sua prática, fundamentando-se em uma base teórica e sólida". Ter acesso às aulas não é incluir, para que haja inclusão é necessário que seja ofertado ao aluno com NEE acessibilidade plena, proporcionando-Ihe educação igualitária diante dos demais estudantes.

$\mathrm{Na}$ perspectiva da educação inclusiva, o Conselho Nacional de Educação, na Resolução CNE/CP n..1/2002, define que as instituições de ensino superior devem prever em sua organização curricular a formação docente voltada para a atenção à diversidade, contemplando conhecimentos sobre as especificidades dos alunos com necessidades educacionais especiais.

No entanto, pôde-se verificar que as dificuldades do aluno sujeito da pesquisa também eram de natureza instrumental e tecnológica, as quais não somente promoveram absoluta falta de acessibilidade no acesso do aluno ao conteúdo das disciplinas, mas também lhe causaram prejuízos, como retenção logo no início do curso.

[...] não tive acesso à biblioteca. [...] fiz um cadastro lá, mas [...] eles não disponibilizavam material adaptado porque não tinham e os que tinham, eram digitalizados em imagens e, [segundo eles] estavam muito ruins. Eu formalizei o pedido à junto a instituição, [...], mas nunca obtive resposta [...]. Isso me prejudicou logo no primeiro período, pois eu não tinha acesso aos conteúdos ministrados pelos professores e acabei ficando retido em uma disciplina. (10.15).

Nos laboratórios de informática da instituição, não existem computadores adaptados com software para deficientes visuais, nem mesmo um técnico 
que esteja disponível para auxiliar pessoas que tenham dificuldade visual na utilização das máquinas. (11.15).

A ABNT NBR 9050, com relação à deficiência visual, dispõe sobre a acessibilidade "[...] que as bibliotecas devem garantir recursos audiovisuais, publicações em texto digital acessível e serviço de apoio, conforme definido em legislação específica. Recomenda-se que possuam também publicações em Braille.” (p. 135).

O pilar da inclusão consiste na ideia de que todos têm direito à educação, sob esse enfoque, deve-se respeitar as necessidades de aprendizagem de cada indivíduo. Pimenta (2017, p. 118) ressalta que "[...] as instituições de ensino devem reconhecer que cada estudante é único, com características específicas, e que, desta forma, precisam ter suas diferenças respeitadas, suas necessidades atendidas, mediante ações que busquem concretizar a inclusão educacional."

Em relação à acessibilidade atitudinal, foram questionados os seguintes pontos:

Na sua opinião, existe intencionalidade por parte dos gestores institucionais de dar visibilidade às ações de inclusão ou alguma articulação que vise manter parcerias para ações e encaminhamentos referentes ao apoio às pessoas com NEE?

"Não, nenhuma intencionalidade por parte dos gestores. Se existe algum tipo de articulação, eu desconheço e acredito ser de desconhecimento de toda a comunidade acadêmica, pois não é divulgado nada a respeito." (12.15).

No Projeto Pedagógico da instituição, é de seu conhecimento se existe destinação de recursos para a implementação da acessibilidade?

"Se existe algum recurso, eu desconheço, não sei onde e nem como é realizada a aplicação desse recurso, [...] nem para [...] quem esse recurso é utilizado [, isto é, destinado]." (13.15).

Dessa forma, fica evidente a falta de acessibilidade atitudinal por parte dos gestores da universidade. Para Holanda e Paiva (2018, p. 115), "[...] na maioria das vezes, essas barreiras são inconscientes e de difícil reconhecimento por parte de quem as pratica, o que dificulta o processo de inclusão deste segmento, principalmente por ser uma prática decorrente da sociedade, o que acaba perpassando o universo educacional."

Em estudos realizados por Silva e Ponte (2015), indicou-se a acessibilidade atitudinal como um dos maiores desafios no processo de inclusão social. Não basta somente abrir as portas para que o aluno tenha acesso a uma graduação, colocar junto é somente integrar o sujeito, não significa fazer parte, para que haja inclusão é necessário que se criem condições de acessibilidade. 
A instituição federal de ensino superior nem sempre estará preparada para receber o aluno com NEE, mas, diante da demanda existente, essa instituição tem obrigação de organizar-se para atendê-lo. Ações, como a implantação de um núcleo de apoio especializado, são de fundamental importância, pois é a partir delas que toda a comunidade acadêmica poderá dispor de suporte para desenvolver um ensino acessível e igualitário.

Após inúmeras solicitações enviadas por mim à instituição exigindo o
cumprimento das leis, o processo de inclusão e acessibilidade, mesmo que
de forma muito lenta, vem avançando. Atualmente, existe um Núcleo de
Acessibilidade, mas ainda não está institucionalizado, o qual possui uma
sala com dois computadores que ainda não estão adaptados, um scanner
de voz a que eu não tenho acesso para utilizá-lo [...], três bolsistas para
serviços administrativos [...] e dois [...] para mobilidade acadêmica. Esse
serviço é relevante na questão da minha mobilidade dentro do instituto,
como a estrutura física não é acessível para minha mobilidade autônoma,
eles trabalham evitando que eu sofra algum acidente, também é relevante
na hora das avaliações na questão da leitura, da transcrição e [...] de
algumas atividades. Dentro da sala de aula e dos laboratórios, existe pouca
relevância, pois, mais uma vez, a falta de formação para os bolsistas e [...]
professores impede que haja inclusão. (14.15).

Verifica-se, no relato do estudante, a dificuldade de ter suas solicitações de acessibilidade atendidas, pois as ações que foram desenvolvidas na universidade só proporcionaram acessibilidade parcial às necessidades do aluno com deficiência visual. $O$ trabalho do núcleo especializado deve ser realizado de forma compromissada, já que é ele o responsável em minimizar as barreiras educacionais encontradas.

O Atendimento Educacional Especial (AEE) prevê, no Decreto n‥ 7.611/11, sobre Art. $5^{\circ}$., $\S 2^{\circ}$., a estruturação de núcleos de acessibilidade nas IFES, tendo como objetivo eliminar barreiras físicas, de comunicação e de informação que dificultam a participação e o desenvolvimento acadêmico e social de estudantes com deficiência.

Submetendo à leitura geral, à leitura geral, a situação de inclusão do aluno em análise revela que as barreiras de acessibilidades, encontradas pelo referido estudante na universidade, são originadas por questões atitudinais, partindo desta a soma de todas as outras, por exemplo: as barreiras na estrutura física do campus, as barreiras de caráter pedagógico e discriminação pela deficiência, que estão apresentadas, conforme o quadro 1, nas tipologias de acessibilidade: atitudinal, arquitetônica, comunicacional, instrumental e programática.

Com base no resultado da análise aplicada no quadro 1, ficou perceptível perfazer um balanço geral da situação de inclusão do aluno com base no resultado, pois ficou perceptível, portanto, que as tipologias de acessibilidade referenciadas no Documento de 
Acessibilidade na Educação Superior, tiveram limitações e até ausência de oferta, impedindo que ocorresse a real inclusão do discente.

Quadro 1 - Tipologias de acessibilidades analisadas na universidade

\begin{tabular}{|c|c|c|}
\hline $\begin{array}{l}\text { ESPECTRO DA } \\
\text { ACESSIBILIDADE }\end{array}$ & DEFINIÇÕES & ANÁLISES \\
\hline Acess. Atitudinal & $\begin{array}{l}\text { Interesse por parte dos gestores da instituição em } \\
\text { implementar ações e projetos relacionados à } \\
\text { acessibilidade em toda a sua amplitude. }\end{array}$ & Limitada \\
\hline Acess. Arquitetônica & $\begin{array}{l}\text { Rampas, piso tátil, sinalização em alto-relevo, } \\
\text { elevadores em condições de uso dentre outros. }\end{array}$ & Limitada \\
\hline $\begin{array}{c}\text { Acess. } \\
\text { Comunicacional }\end{array}$ & Uso de Braile na sala de aula. & Não foi observada \\
\hline Acess. Metodológica & $\begin{array}{c}\text { Processos de diversificação curricular, } \\
\text { flexibilização do tempo e utilização de recursos } \\
\text { para viabilizar a aprendizagem de estudantes com } \\
\text { deficiência. }\end{array}$ & Limitada \\
\hline Acess. Instrumental & $\begin{array}{l}\text { Superação das barreiras nos instrumentos, } \\
\text { utensílios e ferramentas de estudo. }\end{array}$ & Limitada \\
\hline Acess. Programática & $\begin{array}{c}\text { Processos de sensibilização, informação, } \\
\text { conhecimento e a aplicação dos dispositivos } \\
\text { legais e políticas relacionadas à inclusão e à } \\
\text { acessibilidade de estudantes com deficiência na } \\
\text { educação superior. }\end{array}$ & Limitada \\
\hline
\end{tabular}

Fonte: Adaptação da autora a partir do Documento Referenciais de Acessibilidade na Educação Superior e A Avaliação IN LOCO do Sistema Nacional de Avaliação da Educação Superior (SINAES).

Os dados nos põem a atestar que os desafios para o fortalecimento de uma política inclusiva na educação superior são muitos, pois foi possível observar que o participante sujeito desta pesquisa experimentou todos os tipos de dificuldades de acessibilidade, analisados na universidade, no decorrer de sua trajetória. Em outras palavras, o referido 
participante teve acesso ao curso superior, mas o processo de inclusão e acessibilidade para a garantia de uma educação igualitária revelou-se insuficiente.

\section{FATORES QUE GARANTIRAM A PERMANÊNCIA DO ALUNO NO CURSO}

A existência das leis e o conhecimento do aluno sobre elas foram os principais fatores que contribuíram para que o mesmo alcançasse êxito em sua trajetória acadêmica.

O que garantiu a minha permanência no curso foram as legislações, inclusive foram elas que garantiram a minha matrícula compulsória no curso. E também o desejo de eu realizar meus projetos pessoais e a convicção da minha capacidade em superar os meus limites. (15.15).

É necessário que se entenda que a acessibilidade não é somente física, mas é pedagógica e atitudinal. Nessa perspectiva, Ciantelli e Leite (2016) ressaltam a necessidade de articular ações de informação, conhecimento e conscientização dos dispositivos legais e políticas relacionadas à remoção das barreiras a todos os segmentos da comunidade acadêmica, visando a alterações no regimento interno, no projeto políticopedagógico e no plano de desenvolvimento institucional das IFES.

\section{CONSIDERAÇÕES FINAIS}

O retrato que se obteve da realidade de condições de inclusão de um estudante com deficiência visual de uma universidade federal ficou marcado pelo contraste entre a existência da legislação amparadora vigente e a sua prática quase ineficaz. Ainda que se constatasse, por este estudo, que o acadêmico tenha superado as barreiras de aprendizado e usufruído da garantia de sua permanência no curso pela eficiência da lei, de outro lado, veio à tona a inércia de tal legislação, uma vez que o aluno deficiente somente conseguiu ser assistido no momento em que ele próprio tomou a iniciativa de provocar a instituição para se fazerem cumprir os direitos dele. Essa certamente foi a evidência essencial para salientarmos a divulgação dessa problemática e colaborarmos para o aprofundamento da discussão acerca da funcionalidade das políticas de inclusão no Brasil.

Estamos certos de que, ao adotarmos a metodologia utilizada, fundamentando-nos nas políticas de inclusão, nas literaturas pesquisadas e nas análises da entrevista, obtivemos o cumprimento dos objetivos propostos. Não é o grande conjunto de normas jurídicas que dificultam a realização da inclusão e a acessibilidade ao público-alvo, é a atitude dos sujeitos da instituição. Em outras palavras, é a ausência de atitudes assertivas nesse sentido, é a falta de formação, de informação, de fiscalização, de punição para que 
haja o funcionamento da lei. Não é muito diferente daquilo que ocorre com as demais normas legais no Brasil. A lei, portanto, se mostra eficiente, mas não eficaz.

Os avanços na execução de políticas inclusivas conquistados advindos da participação ativa, do esclarecimento do tema, dos estudos e da chamada luta social não regredirão, já que se observa, particularmente, o movimento do aluno indo em busca da efetivação dos seus direitos no cumprimento das legislações de inclusão, no entanto, a universidade, que hoje não atende de forma satisfatória às necessidades educacionais de seu público diversificado, precisa avaliar e refletir sobre sua estrutura físico-pedagógica.

Não cabe, enfim, sermos redundantes em chamar a atenção para a observação das diretrizes curriculares e bases legais da temática em questão pelos integrantes do processo educacional brasileiro, cabe antes concluirmos que as instituições educativas devam assumir o seu dever de incluir toda a sociedade que a compõe, em sua totalidade plural, prevista igualmente nos documentos oficiais, sem esperar que ocorram primeiramente fiscalizações punitivas para começarem a pôr em prática o seu papel de ofertar condições e oportunidades de desenvolvimento pleno de formação dos sujeitos.

\section{REFERÊNCIAS}

ALMEIDA, José Guilherme de Andrade; FERREIRA, Eliana Lucia. Sentidos da inclusão de alunos com deficiência na educação superior: olhares a partir da Universidade Federal de Juiz de Fora. Rev. Psicologia Escolar e Educacional, SP. Número Especial, 2018: 6775.

ANACHE, Alexandra Ayach; CAVALCANTE, Lysa Duarte; Análise das condições de permanência do estudante com deficiência na Educação Superior. Rev. Psicologia Escolar e Educacional, SP. Número Especial, 2018: 115-125.

ANACHE, Alexandra Ayach; MACIEL, Carina Elizabeth; A permanência de estudantes com deficiência nas universidades brasileiras. Educar em Revista, Curitiba, Brasil, v. 33, n. especial 3, p. 71-86, dez. 2017.

ASSOCIAÇÃO BRASILEIRA DE NORMAS TÉCNICAS. NBR 9050: Acessibilidade a edificações, mobiliário, espaços e equipamentos urbanos $\mathbf{- 1 0 . 1 6}$ Bibliotecas e centros de leitura. 10.16.5 p. 134. Rio de Janeiro, 2015.

BRASIL. Decreto Lei no 13.146, de 6 julho 2015. Lei Brasileira de Inclusão. Diário Oficial [da] República Federativa do Brasil, Poder Executivo, Brasília, DF, 6 jul. 2015. Disponível em: $\quad$ <http://www2.camara.leg.br/legin/fed/lei/2015/lei-13146-6-julho-2015-781174normaatualizada-pl.pdf>. Acesso em: 25 maio de 2019.

BRASIL. Ministério da Educação. Documento orientador Programa Incluir - Acessibilidade na Educação Superior. Secadi/Sesu-2013. Brasília/DF, 2013. Disponível em: <http://portal/ mec.gov.br/arquivos/pdf/politicaeducespecial.pdf>. Acesso em: 10 março 2019. 
BRASIL. Presidência da República. Decreto no 6.571, de 17 de setembro de 2008. Brasília, 2008. Disponível em: <http://www2.camara.leg.br/legin/fed/lei/2015/lei-13146-6julho-2015-781174-normaatualizada-pl.pdf>. Acesso em: 25 maio de 2019.

CABRAL, Leonardo Santos Amâncio. Inclusão do público-alvo da Educação Especial no Ensino Superior Brasileiro: histórico, políticas e práticas. Rev. educ. PUC-Camp., Campinas, 22(3):371-387, set./dez., 2017.

CASTRO, Sabrina Fernandes de. Ingresso e Permanência de alunos com deficiência em Universidades Públicas Brasileiras. 197f. Tese (Doutorado em Educação) Programa de Pós-graduação em Educação Especial da UFSCar. São Carlos: UFSCar. 2011.

CIANTELLI, A.P.C. \& LEITE, L.P. Ações Exercidas pelos Núcleos de Acessibilidade nas Universidades Federais Brasileiras, Rev. Bras. Ed. Esp., Marília, v. 22, n. 3, p. 413-428, Jul.-Set., 2016. Disponível em: http://dx.doi.org/10.1590/S1413-65382216000300008. Acesso em: 19 março 2019.

CONTI, Keli Cristina; TURELLA, Celis Ferreira. Matemática e a Deficiência Visual: Atividades Desenvolvidas com Material Dourado. Revista Benjamin Constant. Rio de Janeiro, v.18 número 52, p.16 a 23. 2012.

CRESWELL, John. Investigação Qualitativa e Projeto de Pesquisa: escolhendo entre cinco abordagens. 3ำ edição. Porto Alegre: Ed. Penso, 2014.

ESTRELA, Idalícia Araújo. “Nada sobre nós, sem nós”: a influência da acessibilidade atitudinal no processo de formação de universitários com deficiência visual. Trabalho de conclusão de curso (Bacharelado em Psicologia) - Faculdade Maurício de Nassau, Fortaleza, 2017.

FACHINETTI, Tamires Aparecida. Visão docente e de alunos com deficiência sobre a inclusão na Educação Superior; Dissertação (Mestrado em Educação Escolar) Universidade Estadual Paulista "Júlio de Mesquita Filho", Faculdade de Ciências e Letras (Campus Araraquara). 108 f, 2018.

FERREIRA, Solange Leme. Ingresso, permanência e competência: uma realidade possível para universitários com necessidades educacionais especiais. Revista Brasileira de Educação Especial, v.13, n.1, p.43-60, 2007.

HOLANDA, Monyque Mary Bezerra de; PAIVA, Geórgia Maria Feitosa e. Inclusão de pessoas com deficiência visual na universidade. Rev. Educação em Debate, Fortaleza, ano 40, no 77 - set./dez. 2018.

INSTIUTO NACIONAL DE ESTUDOS E PESQUISAS EDUCACIONAIS ANÍSIO TEIXEIRA. Sinopse Estatística da Educação Superior 2017. Brasília: Inep, 2018. Disponível em: http://portal.inep.gov.br//basica-censo-escolar-sinopse-sinopse. Acesso em: 02 março 2019.

INSTIUTO NACIONAL DE ESTUDOS E PESQUISAS EDUCACIONAIS ANÍSIO TEIXEIRA. Sinopses Estatísticas da Educação Superior 2013. Brasília: Inep, 2014. Disponível em: http://portal.inep.gov.br/sinopses-estatisticas-da-educacao-superior. Acessado em: 02 março 2019. 
NASCIMENTO, Vera Creusa de Gusmão. Quando as “exceções” desafiam as regras: vozes de pessoas com deficiência sobre o processo de inclusão no ensino superior. $102 f$. Dissertação (Mestrado em Educação) - Universidade Federal da Paraíba. João Pessoa, 2011.

NAVARRO, Elaine Cristina; SILVA, Ormenzina Garcia da. Relação Professor-Aluno no Processo Ensino-Aprendizagem, 2012. Interdisciplinar: Revista Eletrônica da Univar (2012) $\quad \mathrm{n} .8$ Vol - 3 p. 95 -100. ISSN 1984-431X. (On-line). Disponível em: <https://docplayer.com.br/16366275-A-relacao-professor-aluno-no-processo-ensinoaprendizagem.html>. Acessado em: 10 Abril 2019.

NEPOMOCENO, Taiane Aparecida Ribeiro; SZEZERBATZ, Rosemari Aparecida Pedroso. Deficiência visual no Ensino superior: O processo de inclusão e as Práticas Pedagógicas. Revista da Educação, Umuarama, v. 18, n. 2, p. 373-395, jul./dez. 2018.

OLIVEIRA, Antônia Soares Silveira e. Alunos com Deficiência no Ensino Superior: subsídios para a política de inclusão da UNIMONTES. 231f. Tese (Doutorado em Educação). - São Carlos: UFSCar, 2011. UFSCar, 2011.

PIMENTA, Cláudia Marisa Ferreira Machado. Acesso e permanência de estudantes com deficiência visual em uma instituição de educação superior. 239 f.: il. Tese (doutorado) - Universidade Federal da Bahia. Faculdade de Educação, Salvador, 2017.

SANTOS, Antônio Carlos Nogueira. Acessibilidade da pessoa com deficiência física: O caso da Universidade Federal de Sergipe. 2012. 123f. Dissertação (Mestrado em Educação). -Cidade Universitária Professor José Aloísio de campos. São Cristóvão: Sergipe. 2012.

TAYAH, David. et al., Retinose Pigmentar. Arquivos Médicos ABC. São Paulo, v. 29, n. 2, 2004, p. 82-86.

YIN, Robert K. Estudo de caso: Planejamentos e métodos. Porto Alegre: Bookman, 2010.

Artigo recebido em: 05 de agosto de 2020.

Aceito para publicação em: 10 de novembro de 2020.

Manuscript received on: August 05, 2020

Accepted for publication on: November 10, 2020

Endereço para contato: Universidade Federal do Amazonas, Faculdade de Educação/FACED, Programa de Pós-

Graduação em Educação, Campus Universitário, Manaus, CEP: 69067-005, Manaus/AM, Brasil 